Article

Subscriber access provided by University of Newcastle, Australia

\title{
Ferritin decorated PLGA/Paclitaxel loaded nanoparticles endowed with an enhanced toxicity towards MCF-7 breast tumour cells
}

Ludmila N. Turino, Maria Ruggiero, Rachele Stefania, Juan

Carlos Cutrin, Silvio Aime, and Simonetta Geninatti Crich

Bioconjugate Chem., Just Accepted Manuscript • DOI: 10.1021/acs.bioconjchem.7b00096 • Publication Date (Web): 16 Mar 2017

Downloaded from http://pubs.acs.org on March 19, 2017

\section{Just Accepted}

"Just Accepted" manuscripts have been peer-reviewed and accepted for publication. They are posted online prior to technical editing, formatting for publication and author proofing. The American Chemical Society provides "Just Accepted" as a free service to the research community to expedite the dissemination of scientific material as soon as possible after acceptance. "Just Accepted" manuscripts appear in full in PDF format accompanied by an HTML abstract. "Just Accepted" manuscripts have been fully peer reviewed, but should not be considered the official version of record. They are accessible to all readers and citable by the Digital Object Identifier (DOI®). "Just Accepted" is an optional service offered to authors. Therefore, the "Just Accepted" Web site may not include all articles that will be published in the journal. After a manuscript is technically edited and formatted, it will be removed from the "Just Accepted" Web site and published as an ASAP article. Note that technical editing may introduce minor changes to the manuscript text and/or graphics which could affect content, and all legal disclaimers and ethical guidelines that apply to the journal pertain. ACS cannot be held responsible for errors or consequences arising from the use of information contained in these "Just Accepted" manuscripts. 


\title{
Ferritin decorated PLGA/Paclitaxel loaded nanoparticles endowed with an enhanced toxicity towards MCF-7 breast tumour cells
}

\author{
Ludmila N. Turino ${ }^{\S}$, Maria R. Ruggiero ${ }^{\dagger,}$, Rachele Stefanìa ${ }^{\dagger}$, Juan C. Cutrin ${ }^{\dagger}$, \\ Silvio Aime ${ }^{\dagger}$, Simonetta Geninatti Crich ${ }^{\dagger *}$. \\ $\S$ Laboratorio de Química Fina, Instituto de Desarrollo Tecnológico para la Industria Química \\ (INTEC), Universidad Nacional del Litoral, Consejo Nacional de Investigaciones Científicas y \\ Técnicas (CONICET), Predio CCT-CONICET, Ruta Nacional 168 Km. 0, (3000) Santa Fe, \\ Argentina. \\ ${ }^{\dagger}$ University of Turin, Department of Molecular Biotechnology and Health Sciences, via Nizza \\ 52, 10126, Turin, Italy \\ \$SAET S.p.A via Torino, 21310040 Leinì, Turin, Italy
}

Corresponding Author

*Simonetta Geninatti Crich, Department of Molecular Biotechnology and Health Sciences, University of Torino, via Nizza 52, 10126, Torino (Italy); tel +39 011 6706473; FAX +39011 6706487; email: simonetta.geninatti@unito.it

ORCID: orcid.org/0000-0003-2998-5424

Author Contributions

The manuscript was written through contributions of all authors. All authors have given approval to the final version of the manuscript. LN. Turino and M.R. Ruggiero contributed equally. 


\begin{abstract}
PolyLactic and Glycolic Acid nanoparticles (PLGA-NPs), coated with L-Ferritin, are exploited for the simultaneous delivery of paclitaxel and an amphiphilic Gd based MRI contrast agent into breast cancer cells (MCF7). L-Ferritin has been covalently conjugated to the external surface of PLGA-NPs exploiting NHS activated carboxylic groups. The results confirmed that nanoparticles decorated with L-Ferritin have many advantages with respect both albumin-decorated and non-decorated particles. Ferritin moieties endow PLGA-NPs with targeting capability, exploiting SCARA5 receptors overexpressed by these tumour cells, that results in an increased paclitaxel cytotoxicity. Moreover, protein coating increased nanoparticle stability thus reducing the fast and aspecific drug release before reaching the target. The theranostic potentiality of the nanoparticles has been demonstrated by evaluating the signal intensity enhancement on $\mathrm{T}_{1}$-weighted MRI images of labelled MCF7 cells. The results were compared with that obtained with MDA cells used as negative control due to their lower SCARA5 expression.
\end{abstract}

Keywords. Polylactic and glycolic (PLGA) nanoparticles; Ferritin, Gd based contrast agents, MRI, Paclitaxel, breast cancer. 


\section{INTRODUCTION}

Nanotechnology is under intense scrutiny in the design of new medical protocols, as a significant improvement of diagnoses and therapy ${ }^{1}$, in particular of cancer and cardiovascular diseases, is expected from the application of nanosized drug delivery systems ${ }^{2}$. In this contest, liposomes, solid-lipid nanoparticles, and biodegradable polymeric nanoparticles are the most widely investigated systems. Poly (D, L-lactide-co-glicolide) (PLGA) has attracted great attention in the design of nanosized delivery systems because of its excellent biocompatibility and biodegradability, associated to the presence of ester linkages that undergo slow hydrolysis in aqueous system ${ }^{3}$. The removal of nanosized drug carriers from the body, due to their hydrophobic nature, by the Mononuclear Phagocyte System is a major obstacle that hinders the application of these drug delivery systems ${ }^{4}$. Therefore surface modification and coating of PLGA nanoparticles is the subject of studies aimed at prolonging their circulation lifetime. The most commonly used strategy to obtain stealth nanoparticles is based on the use of PEG and it has led to the development of several products that are currently in clinical use ${ }^{5}$. However, the recent observation of anti-PEG immunological response ${ }^{6}$ has motivated a renewed interest towards the research for alternative strategies. Among possible surface modification of PLGA nanoparticles, serum albumin has received some attention due to its relatively small size, hydrophilic surface and accumulation in leaky vasculature of tumours through passive targeting ${ }^{7-9}$. PLGA nanoparticles coated with serum albumin showed an improved stability and when loaded with the anti-tumoral paclitaxel drug, a more efficient delivery to tumour cells. Herein we report results concerning the use of Ferritin as alternative protein coating for PLGA surface. In addition to act as a hydrophilic cover, Ferritin may endow the nanoparticle with a potential targeting capability thus improving the uptake from the tumour cells through specific ferritin receptors. Ferritin is the main iron storage protein and is composed of 24 subunits of heavy $(\mathrm{H})$ - or light (L)-chain polypeptides that are present at different ratios in various organs to form a cage architecture of $12 \mathrm{~nm}$ in external diameter, with an inner cavity of $8 \mathrm{~nm}^{10}$. Ferritin functions are traditionally associated with intracellular iron storage but additional functions related to iron delivery based on a transferrin-independent mechanism to different target organs (such as brain, liver and spleen) have been recently discovered and investigated ${ }^{11}$. The involved receptors belong to scavenger receptor class A member 5 (SCARA5) ${ }^{12-14}$ for L-ferritin and to TIM-2 ${ }^{15}$ and $\mathrm{TfR}-1^{16,17}$ for $\mathrm{H}$-ferritin, in mice and human, respectively. Based on evidence attained from both 
epidemiological and molecular studies, new insights are linking the presence of excess iron and altered iron metabolism to cancer as a consequence of the rapid cell proliferation ${ }^{18}$. It is well known that, many cancer cells reprogram iron metabolism in ways that result in net iron influx ${ }^{19}$. This occurs through the up-regulation of the expression of proteins that are involved in iron uptake (i.e. TfR1, SCARA5) and the decreased expression of iron efflux proteins, such as ferroportin. The relationship between ferritin and cancer is well supported by studies showing an increase of the total ferritin (rich in L-chains) in the blood serum ${ }^{20}$. For example, in breast cancer patients, it was found a correlation with ferritin increase and the stage of the disease, as the high serum concentration of the protein is associated with the release within the breast tumor microenvironment ${ }^{21}$. Accordingly, breast tumor lysates also show elevated levels of L-ferritin, the predominant subunit observed in serum, and this increase correlates with advanced histological grade and poor outcome ${ }^{22,23}$. There are many examples in the literature exploiting ferritin for the delivery of water soluble drugs and imaging agents loaded in its inner aqueous cavity $^{24-27}$. In this context, we have previously reported that native horse spleen Ferritin (composed by $85 \%$ and $15 \% \mathrm{~L}$ and $\mathrm{H}$ chains, respectively) is selectively taken-up by the human breast cancer cell line MCF7 through SCARA5 receptors ${ }^{28}$.

On this basis herein we propose the use of ferritin as simultaneous targeting and coating agent for PLGA nanoparticles, able to deliver selectively paclitaxel (PTX), a cytostatic compound with very low water solubility, to breast cancer (MCF-7 cells). Horse spleen ferritin has been covalently conjugated to the external surface of PLGA nanoparticles exploiting NHS activated carboxylic groups (Figure 1A). Moreover, PLGA nanoparticles have been loaded with a Gd based MRI imaging agent (Gd-DOTAMA, Figure 1B), in order to monitor their distribution. The performance of ferritin functionalized PLGA nanoparticles has been compared with the corresponding albumin coated ones as well as with unfunctionalized particles. 
1

2

3

4

5

6

7

8

10

11

12

13

14

15

16

17

18

19

20

21

22

23

24

25

26

27

28

29

30

31

32

33

34

35

36

37

38

39

40

41

42

43

44

45

46

47

48

49

50

51

52

53

54

55

56

57

58

59

60

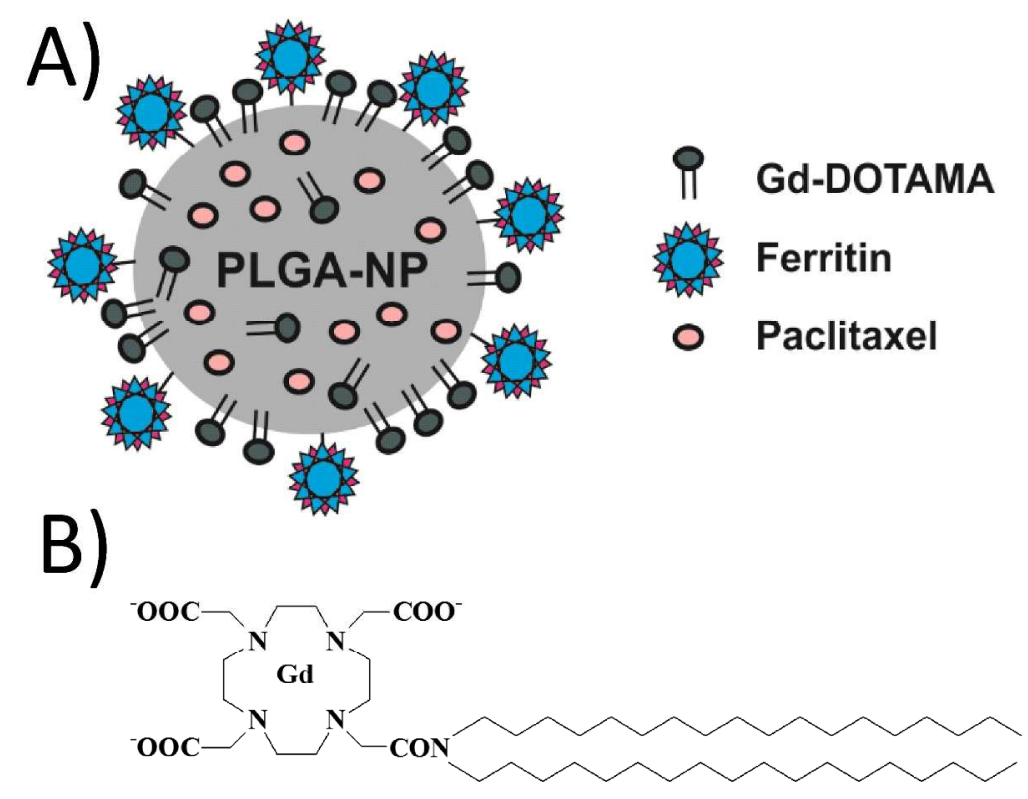

Figure 1. A) Schematic representation of PLGA-Ferr nanoparticles; B) Schematic representation of Gd-DOTAMA. 


\section{RESULTS AND DISCUSSION}

\section{Preparation of PLGA nanoparticles (PLGA-NPS)}

PLGA is one of the most attractive biodegradable and biocompatible polymer that has been used in a number of applications, ranging from drug delivery to tissue engineering ${ }^{29}$. PLGA nanoparticles are characterized by a hydrophobic core that enables entrapping water insoluble hydrophobic molecules. PLGA-NPs were obtained by the $\mathrm{o} / \mathrm{w}$ emulsion solvent extraction method. The organic phase was prepared by dissolving PLGA or PLGA-NHS and GdDOTAMA complex in chloroform ${ }^{30}$. The water phase was a poly vinyl alcohol (PVA) aqueous solution. PVA is the most commonly used emulsifier for the preparation of PLGA-based NPs because it yields particles that are relatively uniform, small sized, and easy to be re-dispersed in water $^{31}$. The organic phase was added to the aqueous phase, and then the resulting mixture has been extensively sonicated. The nanoparticles were obtained by the slow organic solvent evaporation of the o/w emulsion. Then, ferritin (Horse Spleen Ferritin) or bovine serum albumin (BSA) were covalently conjugated to PLGA-NHS nanoparticles exploiting the reaction of PLGA-NHS with the amine groups present on the proteins external surface ${ }^{32-34}$. Before conjugation Ferritin was purified by gel filtration chromatography to eliminate high molecular weight aggregates whereas BSA was used without further purification. The reaction was carried out overnight, at room temperature, under magnetic stirring. Pure PLGA-Ferr and PLGA-BSA have been obtained after size exclusion chromatography (see supporting Information, Figure S1). Control nanoparticles (PLGA-CTRL), without protein coating, were synthesized following the same synthetic protocol using the commercially available PLGA with unconjugated carboxylic groups. As reported in Table 1 both the average PLGA hydrodynamic diameters (measured by dynamic light scattering) and the longitudinal relaxation rate of water protons $\left(1 / \mathrm{T}_{1}\right)$ of the conjugated nanoparticles were unaffected by the protein conjugation. The amount of Ferritin or BSA bound to PLGA-NPs after size exclusion chromatography purification was of $0.23 \pm 0,04$ and $0.21 \pm 0.03 \mathrm{mg} / \mathrm{ml}$, respectively, which represent approximately $121 \pm 25$ Ferritin and $763 \pm 83$ BSA molecules per NPs, respectively. Interestingly, one may observe that the ratio between the amount of Ferritin and BSA bound to PLGA-NPs corresponds approximately to the ratio of the molecular weights of the two proteins. In order to rule out the occurrence of a non-covalent adsorption of the proteins on the PLGA surface, as reported in literature for serum proteins ${ }^{35,36}$, 
non-activated PLGA-CTRL were incubated overnight in the presence of the same amount of Ferritin and BSA. The obtained solutions were purified by gel filtration using the same protocol. In the solutions of purified nanoparticles the protein concentrations was in both cases under the detection limit $(0.034 \mathrm{mg} / \mathrm{ml})$. The low absorption is the consequence of the lower albumin (BSA) concentration incubated $(2 \mathrm{mg} / \mathrm{ml})$ and the negative Z-potential of PLGA-CTRL ($3.9 \pm 1.5$ ). The number of GdDOTAMA loaded in one nanoparticle (ca. $1 \times 10^{5}$ ) is of the same order of those reported for liposomes or other nanoparticles embedded with contrast agents in their interior and not only on their surface ${ }^{37,38}$.

Table 1. Hydrodynamic particle diameter measured by DLS at $25^{\circ} \mathrm{C}$ in $H B S$ Buffer and Polidispersity Index (PDI) of PLGA-CTRL, PLGA-Ferr and PLGA-BSA are reported together with their millimolar relaxivities $\left(\mathrm{mM}^{-1} \mathrm{~s}^{-1}\right)$ and of Gd-DOTAMA and protein encapsulation yields. The table shows the mean \pm SEM of 5 independent experiments

\begin{tabular}{|c|c|c|c|}
\hline & PLGA-CTRL & PLGA-Ferr & PLGA-BSA \\
\hline SIZE (nm) & $152 \pm 8$ & $157 \pm 9$ & $154 \pm 14$ \\
\hline PDI & $0.193 \pm 0.024$ & $0.214 \pm 0.043$ & $0.141 \pm 0.007$ \\
\hline $\mathbf{r}_{1 \mathbf{p}}$ (mM $^{-1} \mathbf{s}^{-\mathbf{1})}$ & $26.6 \pm 1$ & $29.3 \pm 0.93$ & $29.7 \pm 0.3$ \\
\hline Gd-DOTAMA (\%) & $57 \pm 14$ & $38 \pm 10$ & $39 \pm 11$ \\
\hline Protein (\%) & & & $3.7 \pm 0.8$ \\
\hline Number of Proteins/NP & & $121 \pm 25$ & $7.7 \pm 0.7$ \\
\hline Number of Gd/NP & $1.0 \times 10^{5} \pm 0.1 \times 10^{5}$ & $1.3 \times 10^{5} \pm 0.3 \times 10^{5}$ & $1.0 \times 10^{5} \pm 0.15 \times 10^{5}$ \\
& & & \\
\hline
\end{tabular}


Cellular Uptake of PLGA-Ferr and PLGA-BSA by human breast cancer cell lines.

The uptake of PLGA-Ferr and PLGA-BSA was assessed in human breast cancer cells MCF-7 and MDA-MB-231, respectively. As already well established ${ }^{28}$, MCF7 express a relatively high concentration of SCARA5 receptors on their cytoplasmatic membrane, able to internalize LFerritin, whereas MDA-MB-231 has been used as negative control $^{28}$. Cells were incubated in the presence of PLGA-BSA and PLGA-Ferr for $6 \mathrm{~h}$ at $37{ }^{\circ} \mathrm{C}$ and $5 \% \mathrm{CO}_{2}$. The amount of $\mathrm{Gd}$, as determined by ICP-MS, is taken as reporter of the extent of cell internalized PLGA nanoparticles. Figure 2A shows the amount of internalized Gd normalized to the total protein cell content. The values of internalized Gd were significantly higher for MCF-7 incubated in the presence of PLGA-Ferr than PLGA-BSA ( $\mathrm{p}<0.0241)$. On the contrary, Gd uptake into MDAMB-231 cells was lower and not significantly different for the two types of nanoparticles ( $p$ $<0.249$ ). This is in agreement with the fact that these cells express lower SCARA5 receptors than MCF $-7^{28}$. Furthermore, the specificity of the uptake was supported by carrying out a competition study in which the MCF7 cells were incubated with PLGA-Ferr for $6 \mathrm{~h}$ in the presence of an excess ( 75 folds) of native Ferritin. The Gd uptake, measured by ICP-MS, decreased for about $80 \%$ as shown in Figure 2B.
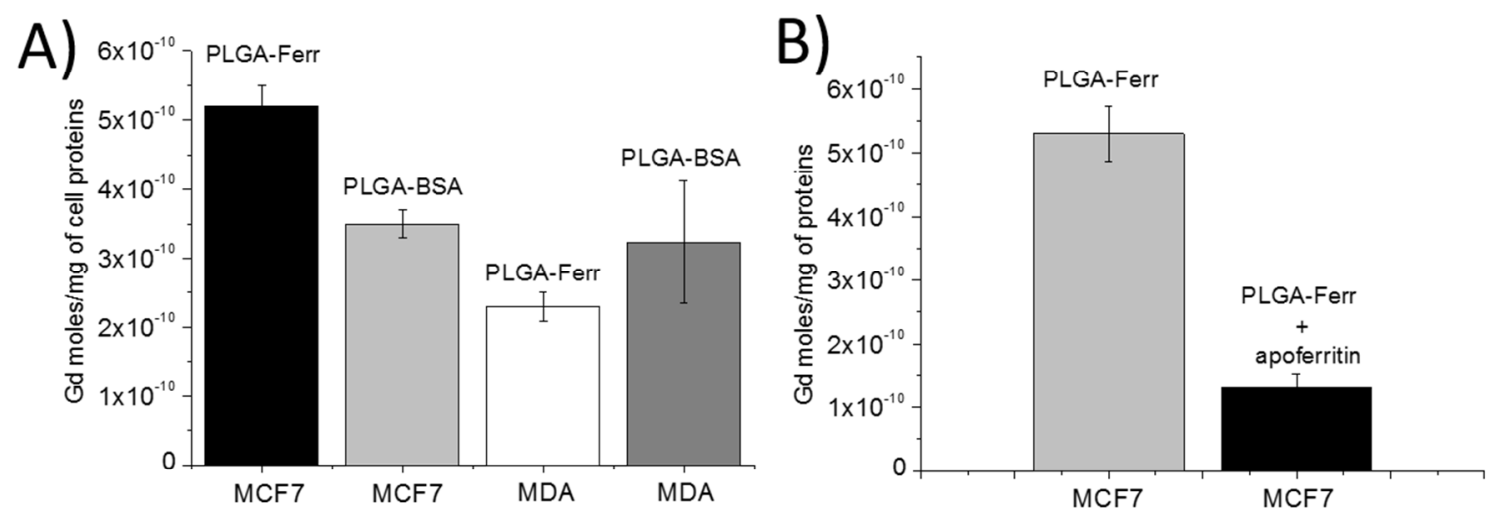

Figure 2. (A) ICP-MS determination of the intracellular $G d$ content of MCF7 and MDA-MB-231 cells cultured for $6 \mathrm{~h}$ with PLGA-Ferr and PLGA-BSA $50 \mu \mathrm{M}$ in $\mathrm{Gd}$. (B) Competition experiment on MCF7 cells. ICP-MS measurements of intracellular Gd were done with or without the addition of an excess (75 times) of native ferritin. Graphs show the mean \pm SEM of internalized Gd moles every $m g$ of total cell proteins from 3 independent experiments. 
Magnetic Resonance Imaging (MRI)

In order to assess whether Gd-labelled PLGA-NPs can generate a sufficient MRI contrast for targeted cells MCF7 and MDA-MB-231, $\mathrm{T}_{1}$-weighted MR images were acquired on cellular pellets obtained upon incubation with PLGA-Ferr and PLGA-BSA (50 $\mu \mathrm{M}$ of Gd), respectively. Figure 3A shows that MCF-7 incubated with PLGA-Ferr displayed markedly higher signal intensity when compared to untreated cells or treated with PLGA-BSA. Only small changes in signal intensity (SI) were observed in MDA-MB-231 cells incubated in the absence or in the presence of PLGA-Ferr and PLGA-BSA, respectively. The differences among the relaxation rates $\left(\mathrm{s}^{-1}\right)$ (Figure $3 \mathrm{~B}$ ) measured on the cell pellets reflected the observed difference in PLGAFerr uptake by MCF-7 and MDA-MB-231 as expected by their different expression of ferritin receptors.
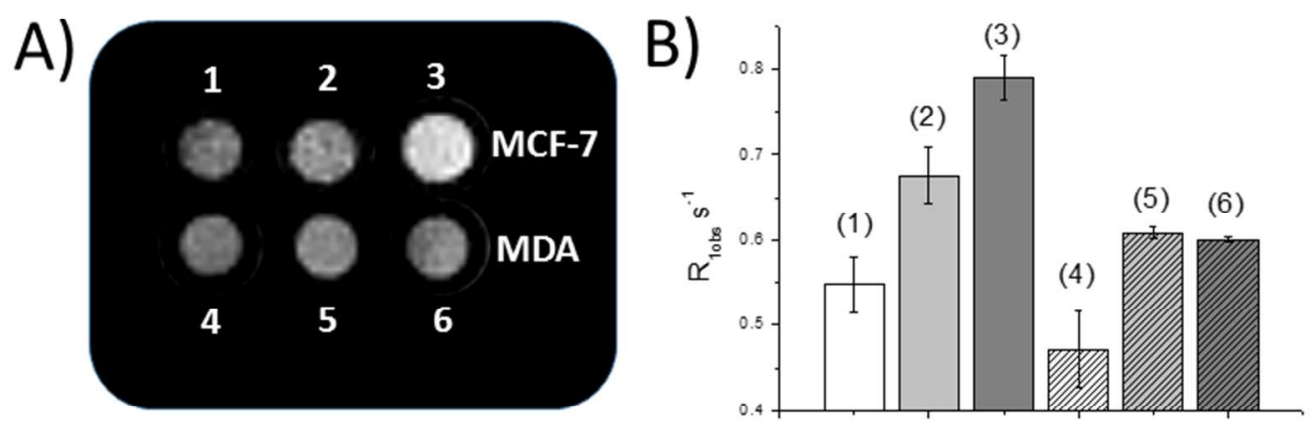

Figure 3. A) Representative $T_{1}$-weighted spin echo image (acquired at 7T) of glass capillaries containing MCF7 $(1,2,3)$ and MDA-MB-231 (4,5,6) cells incubated for 6 hours in the absence (1,4 controls) and in the presence of PLGA-BSA (2,5) and PLGA-Ferr (3,6). B) $R_{1 o b s}\left(s^{-1}\right)$ measured on cell pellets using a saturation recovery sequence. The histogram shows the mean \pm $S D$ of $R_{\text {lobs }}$ from 3 independent experiments.

Loading of Paclitaxel in PLGA-NPS. 
In order to design a "theranostic" system containing both imaging and therapeutic agents, paclitaxel (PTX) has been added to the previously described PLGA-NPs. Paclitaxel is a drug largely used in the treatment for various types of cancer, including ovarian cancer, breast cancer, non-small cell lung cancer and Kaposi's sarcoma ${ }^{39}$. PTX is characterized by a low solubility in water and it is administered to patients in a micellar formulation based on macrogolglycerol ricinoleate dissolved in ethanol ${ }^{40,41}$. The preparation of PLGA-PTX nanoparticles was performed using the same procedure described above. PTX was dissolved in chloroform together with PLGA or PLGA-NHS and Gd-DOTAMA at an initial PTX amount corresponding to $10 \% \mathrm{w} / \mathrm{w}$ (with respect to PLGA). Then pre-formed PLGA nanoparticles were conjugated with the protein (Ferritin or BSA). The PTX encapsulation yields, determined by HPLC, were 6.88 \pm 0.98 , 9.95 \pm 1.5 , and 27.9 $\pm 16( \pm$ SEM) for PLGA-PTX-BSA, PLGA-PTX-Ferr and PLGA-PTX-CTRL, respectively. The significantly lower values found after proteins conjugation with respect to the unfuctionalized PLGA-PTX-CTRL appears due to the fact that a not negligible amount of nanoparticles went lost during the HPLC purification procedure. In fact, the differences are significantly reduced if the PTX loading efficiency is expressed as Gd/PTX \% $(21 \pm 10,23 \pm 14,16$ $\pm 3.8 \pm$ SEM for PLGA-PTX-BSA, PLGA-PTX_Ferr, and PLGA-PTX_CTRL respectively). In vitro drug release from PLGA nanoparticles was evaluated at different intervals of time under dialysis in 1L PBS buffer, as shown in Figure 4. It appears evident that PTX is released more slowly from PLGA-PTX-Ferr and PLGA-PTX-BSA than from PLGA-PTX-CTRL (15 $\pm 3.4 \%$, $20 \pm 4.5 \%$ and $40 \pm 2.25 \%$ within $6 \mathrm{~h}$, respectively $( \pm \mathrm{SEM})$. 


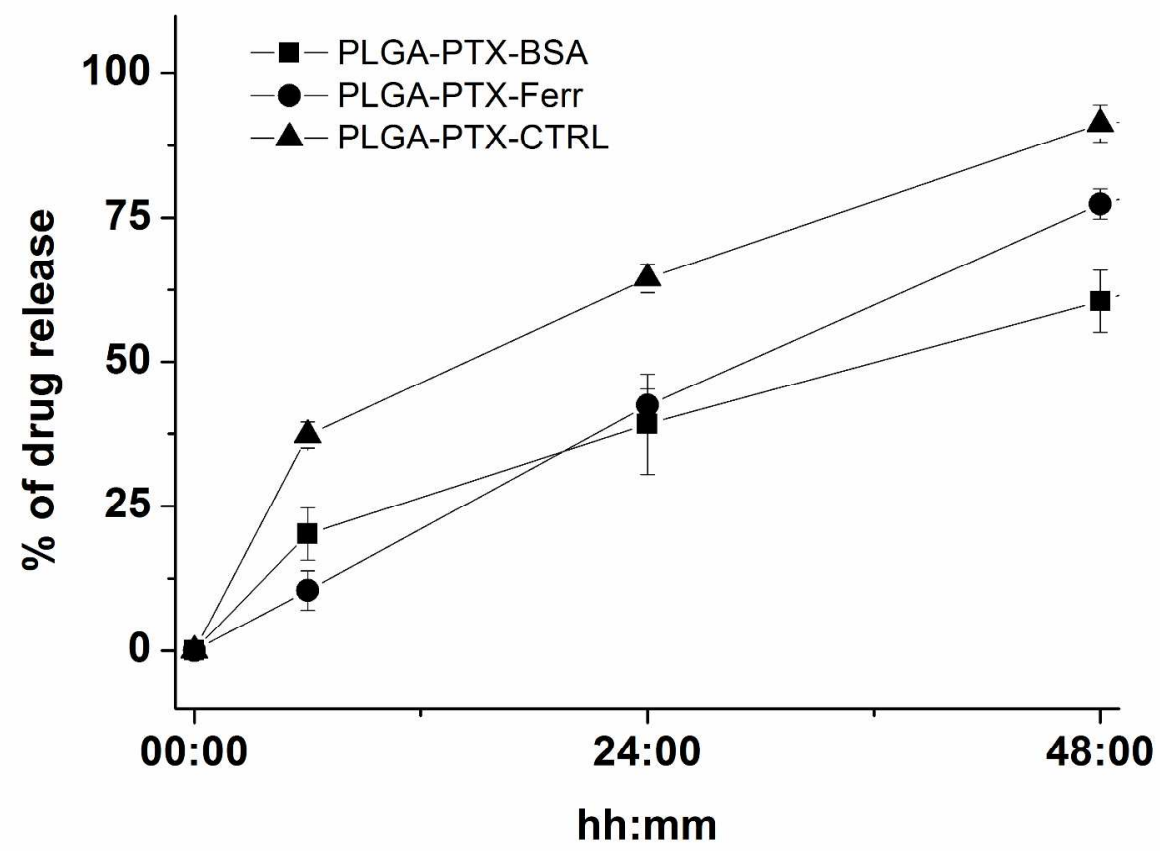

Figure 4: In vitro drug release from PLGA-PTX-CTRL, PLGA-PTX-Ferr and PLGA-PTX-BSA evaluated at different time $(6,24,48 h)$ under dialysis in $P B S$ at $37^{\circ} \mathrm{C}, \mathrm{pH}=7.4$. Graphs show the mean $\pm S D$ of $\%$ PTX release obtained by 3 independent experiments.

PTX release from nanoparticles depends on drug diffusion at the PLGA surface that, in turn, is affected by "bulk" erosion or swelling ${ }^{42}$. The PTX release behavior from the herein developed nanoparticles exhibited a biphasic pattern characterized by an initial rapid release during the first $24 \mathrm{~h}$, followed by a slower and continuous release. The high initial burst release can be attributed to the dissolution of PTX physically adhered at the surface or located at the first layers of the solid nanoparticles ${ }^{40}$. It is likely that the presence of Ferritin or BSA on the surface of PLGANPs slowed down this burst release compared to PLGA-PTX-CTRL Furthermore, the presence of protein on the outside layer of NPs could slowdown diffusion of hydrophobic PTX to the outside medium, making release slower compared to NP without protein coating. Also, the increasing diffusional distance for PTX molecule may delay the drug release from the core of the NPs ${ }^{9,43-45}$. 


\section{Toxicity test of PLGA-PTX nanoparticles}

Viability assays were performed on MCF-7, as they showed a good capability to take-up PLGAPTX-Ferr nanoparticles. Cells were incubated in the presence of PLGA-PTX_Ferr, PLGA-PTXBSA, PLGA-PTX-CTRL and a commercially available Paclitaxel formulation administered to human patients (Paclitaxel Kabi) at increasing concentrations for $6 \mathrm{~h}$ and $24 \mathrm{~h}$ (Figure 5A,B). The range of concentrations of PTX corresponds to plasma levels of the drug achievable in humans ${ }^{46}$. As mentioned above, Paclitaxel Kabi is a water soluble paclitaxel formulation containing macroglycol ricinolate. In agreement with that previously reported by Esfandyari-Manesh and coworkers $^{7}$, we found that the toxicity, herein evaluated by MTT assay, of PLGA coated with BSA and loaded with PTX (PLGA-PTX-BSA) is significantly higher than the one observed for the commercially available Paclitaxel Kabi and for the PTX loaded PLGA-PTX-CTRL. The observed behavior may be accounted for the presence of gp60 (albondin) receptor and caveolar transport as both systems are involved in the transendothelial cell transport of albumin ${ }^{7}$. The data reported in Figure 5 show that the cytotoxicity is further enhanced by using PLGA coated with Ferritin that targets tumor cell more efficiently via the up regulation of SCARA5 receptors. The percent viability of MCF-7 incubated for 6h with PLGA-Ferr, PLGA-BSA, PLGA-CTRL and Paclitaxel Kabi (all at a final PTX concentration $20 \mu \mathrm{M}$ ) were 56\%, 83.5\%, 89\% and 97\%, respectively (Figure 5). 


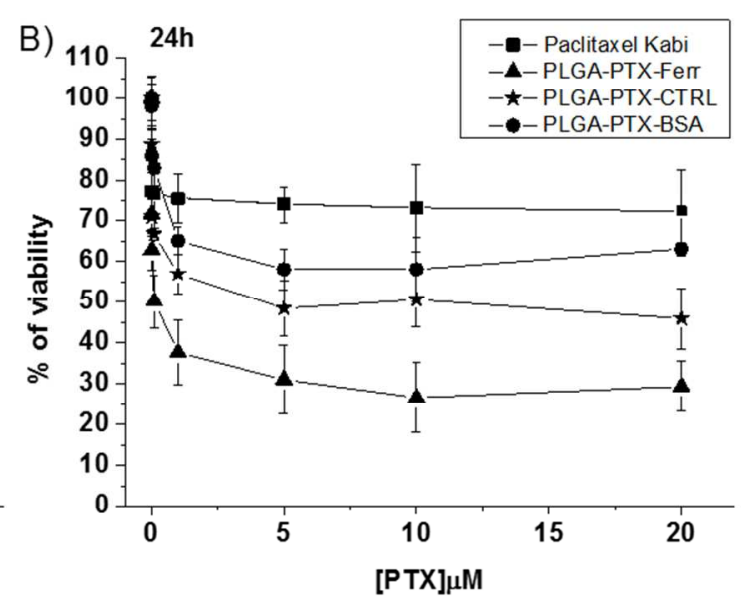

Figure 5: Percentage of viability (measured with MTT assay) of MCF-7 after 6h (A) and 24h (B) of incubation at different concentration of PLGA-PTX-CTRL, PLGA-PTX-Ferr, PLGA-PTX-BSA and Paclitaxel Kabi. Graphs show the mean \pm SEM of \% viability evaluated on 3 independent experiments.

The low toxicity of the commercial drug is very likely due to the short treatment time, only $6 \mathrm{~h}$, which does not lead to enough internalized drug to have detectable cytotoxic effect. In fact, several experiments are reported in the literature where the therapeutic treatment is continued for more than 24 hours $^{41}$. While the percent viability of MCF-7 after $24 \mathrm{~h}$ of incubation at $20 \mu \mathrm{M}$ of PTX with PLGA-PTX-Ferr, PLGA-PTX-CTRL, PLGA-PTX-BSA, and Paclitaxel Kabi were $29 \%, 45 \%, 63 \%$ and $72 \%$ (Figure 5B). The cytotoxicity of nanoparticles not loaded with paclitaxel was evaluated (see supplementary information, Figure S4) and it was less than 10\% for all the PLGA-NPs after 6 and 24h incubation. Nanoparticles with or without PTX were incubated with cells at the same Gd concentration. In order to prove the selective toxic effect of PLGA-PTX-Ferr for tumor cells a comparative cytotoxicity study was done on the human mammary non-tumorigenic epithelial cell line MCF-10A using the same protocol described above. Figure 6 shows clearly that PLGA-PTX-Ferr are significantly more toxic for tumor cells (MCF7) than healthy MCF-10A after 6 and 24h incubation. From these results one draws the conclusion that the specific uptake of PLGA-PTX-Ferr by breast cancer cells (MCF7) allows to increase the therapeutic output of PTX thus overcoming some limitation currently encountered in the clinical use of this drug. Indeed, despite of a wide spectrum of antitumor activity of PTX, its 
therapeutic application in cancer therapy is still hampered by its low aqueous solubility (that necessitates the use of Cremophor ${ }^{\circledR}$ EL, a noninonic solubiliser and emulsifier where the main component is glycerol polyethylene glycol ricinolate) and poor accumulation at the target tumor cells ${ }^{38,39}$.

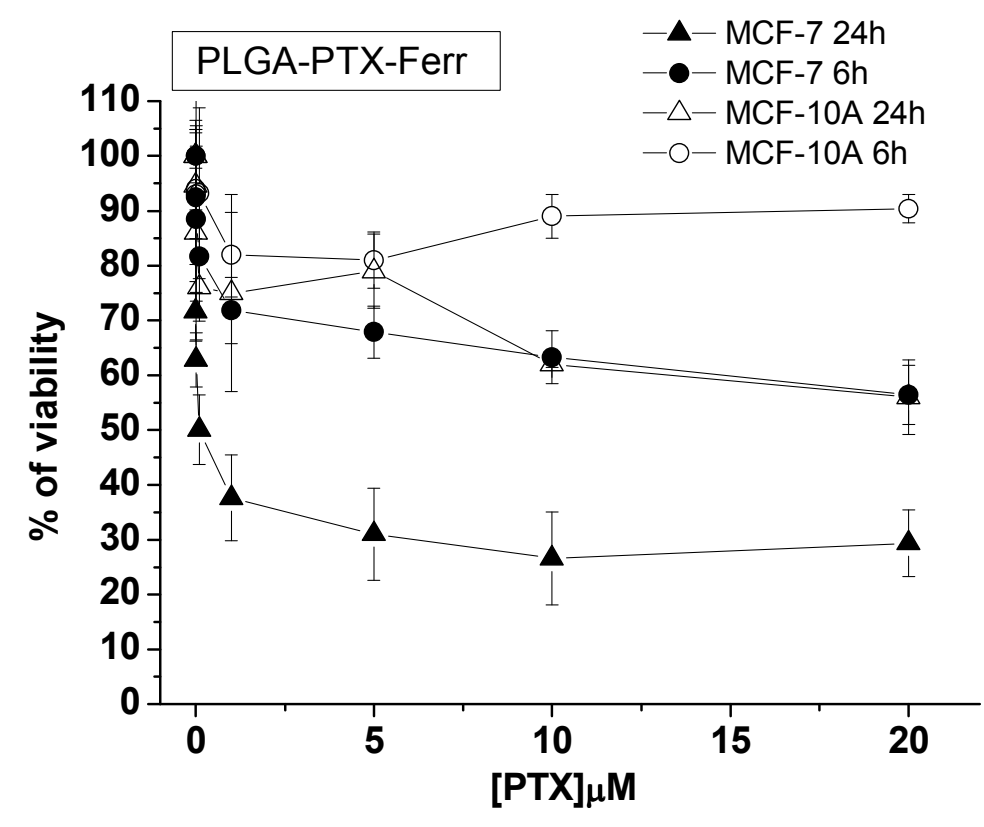

Figure 6. Percentage of viability of MCF-7 and MCF-10A after 6h and 24h of incubation at different concentration of PLGA-PTX-Ferr. Graphs show the mean \pm SEM of \% viability evaluated on 3 independent experiments.

\section{CONCLUSIONS}

In this work it has been shown that the novel drug delivery system based on hydrophobic PLGA nanoparticles decorated with Ferritin has many advantages with respect non decorated particles. Ferritin moieties endow the PLGA-NPs with a targeting capability that, in turn, results in an increased cytotoxicity. Although we have considered only the aggressive breast cancer represented by MCF-7 cell line, it is reasonable to expect that similar results could be obtained from any tumour whose cells overexpress Ferritin transporters. Moreover, protein coating increases the stability of the nanoparticle thus avoiding the fast and aspecific drug release before 
reaching the target. Finally, the versatility of the PLGA nanoparticles permits the combination of therapy and diagnosis by entrapping MRI contrast agents inside the PLGA-NPs hydrophobic core, in a single drug delivery system.

\section{EXPERIMENTAL PROCEDURES}

\section{Materials}

Poly (D,L-lactide-co-glicolide) (PLGA) RG 502H 50:50, molecular weight (MW) 30 000-60 000 Da, and poly(vinyl alcohol) (PVA), MW 31 000-50 000 Da (98\%-99\%hydrolyzed), Ferritin from equine spleen (Ferr), Albumin from bovine serum (BSA), insulin, Thiazoly Blue Tetrazolium Bromide (MTT), N-ethyl-N'-(3- (dimethylamino)propyl) carbodiimide (EDC), Nhydroxysuccinimide (NHS) and acetonitrile were provided by Sigma-Aldrich. Paclitaxel (PTX) was purchased from Aurisco Pharmaceutical Limited (China), while the Paclitaxel Kabi from Fresenius Kabi AG (Italy). The lipophilic Gd-DOTAMA (Figure 1B was synthesized according to a previously reported procedure ${ }^{45}$. Human breast cancer cell lines (MDA-MB-231 and MCF7) were obtained from ATCC. DMEM and EMEM media, Fetal Bovine Serum (FBS), penicillin, streptomycin, L-glutamine, non-essential amino acid, sodium pyruvate, and MycoAlert ${ }^{\mathrm{TM}}$ PLUS Mycoplasma Detection Kit, were obtained from Lonza (Belgium).

\section{Synthesis of N-hydroxysuccinimide activated PLGA (PLGA-NHS).}

PLGA polymer (100 mg, 0.0025mmol) was dissolved in $\mathrm{CH}_{3} \mathrm{CN}(1 \mathrm{ml})$. EDC (20 mg, $\left.0.1 \mathrm{mmol}\right)$ and NHS (10 mg, $0.09 \mathrm{mmol})$, both dissolved in $\mathrm{CH}_{3} \mathrm{CN}(0.5 \mathrm{ml})$ were subsequently added, to PLGA solution. The reaction was left to stir at room temperature for $12 \mathrm{~h}$. The product was precipitated in diethyl ether and washed several times with diethyl ether/methanol (1:1) and dried under vacuum. The ${ }^{13} \mathrm{C}-\mathrm{NMR}(600 \mathrm{MHz}, \mathrm{CDCl})$ was used to assess the formation of the NHS ester (Figure S2 in Supporting Information). The disappearance of the carboxyl groups at 174.2 and $171.8 \mathrm{ppm}$, corresponding to the PLGA carboxylic acid groups, proved the formation of NHS ester.

\section{Preparation of PLGA-NPs}


PLGA-NPs were obtained using an oil-in-water $(\mathrm{o} / \mathrm{w})$ emulsion solvent extraction method. The emulsion was prepared by dissolving $25 \mathrm{mg}$ of PLGA-NHS, $3.5 \mathrm{mg}$ of Gd-DOTAMA in $0.5 \mathrm{ml}$ of chloroform; this solution was called phase 1 . Phase 2 consisted of $3 \% \mathrm{w} / \mathrm{v}$ PVA aqueous solution $(3 \mathrm{ml})$. Phase 1 was added into phase 2 drop by drop and sonicated with a sonicator tip for $300 \mathrm{~s}$ at $100 \%$ power. Final emulsion was transferred to a $50 \mathrm{ml}$ round-bottomed flask and put into a rotary evaporator at $740 \mathrm{mmHg}$ and $30 \mathrm{rpm}$ for $120 \mathrm{~min}$ to remove the organic solvent.

\section{Purification of Ferritin}

$1 \mathrm{ml}$ of commercial Ferritin was purified to eliminate its high molecular weight aggregates by size exclusion chromatography, using an AKTA FPLC Purifier system, equipped with UV-Vis detector (set at 215, 280, and $350 \mathrm{~nm}$ ). Superose 6 10/300 GL was used as column and HBS buffer (1.8 mM Hepes and $150 \mathrm{mM} \mathrm{NaCl}, \mathrm{pH} 7.4)$ as eluent at a flow rate of $0.5 \mathrm{~mL} \mathrm{~min}^{-1}$. The fraction which corresponded to ferritin monomer $\left(440 \mathrm{KDa}, \mathrm{V}_{\mathrm{R}}=13.2 \mathrm{ml}\right)$ were collected and concentrated with vivaspin filters (Sartorius) (MWCO $10000 \mathrm{Da}$ ). The final concentration of protein was determined by means of the Bradford assay, using bovine serum albumin as a standard.

\section{Conjugation of Ferritin or Bovine Serum Albumin (BSA) to PLGA-NPs}

A solution of BSA or Ferritin in PBS $(10 \mathrm{mg} / \mathrm{ml})$ was added to PLGA-NPs solution immediately after nanoparticles preparation using a PLGA/protein ratio of 2.5:1 (25mg/10mg). The conjugation reaction between protein and PLGA-NPs was carried out at room temperature overnight under magnetic stirring. The reaction solution was centrifuged at $5000 \mathrm{rpm}$ for $10 \mathrm{~min}$ and then purified by size exclusion chromatography using the same purification protocol used for ferritin. Chromatograms before and after purification are reported as supporting Information (Figure S1). The collected fractions corresponding to conjugated PLGA-NPs $\left(\mathrm{V}_{\mathrm{R}}=6.5 \mathrm{ml}\right.$ ) were concentrated with vivaspin filters (Sartorius) (MWCO $10000 \mathrm{Da}$ ) by centrifugation at $5000 \mathrm{rpm}$. The amount of Gd-DOTAMA entrapped in the PLGA-NPs was determined by using inductively coupled plasma mass spectrometry (ICP-MS; element-2; Thermo-Finnigan, Rodano (MI), Italy). Sample digestion was performed with concentrated $\mathrm{HNO}_{3}(70 \%, 1 \mathrm{ml})$ under microwave heating (Milestone MicroSYNTH Microwave labstation). The hydrated mean diameter of conjugated PLGA-NPs were determined using a dynamic light scattering (DLS) Malvern Zetasizer 3000HS 
(Malvern, U.K.) All samples were analyzed at $25{ }^{\circ} \mathrm{C}$ in filtered (cutoff, $200 \mathrm{~nm}$ ) $\mathrm{NaCl} 10 \mathrm{mM}$ buffer ( $\mathrm{pH}$ 7.4). The relaxivity $\left(\mathrm{r}_{1 \mathrm{p}}\right)$ at $21.5 \mathrm{MHz}$ and $25{ }^{\circ} \mathrm{C}$ was determined by ${ }^{1} \mathrm{H}$ nuclear magnetic resonance $T_{1}$ measurement (Stelar Spinmaster, Mede, Italy) by means of the inversion recovery method (16 delays values, two averages). The reproducibility of the $\mathrm{T}_{1}$ data was $\pm 5 \%$. The amount of conjugated proteins was determined by means of the Bradford assay, using bovine serum albumin as a standard. The average number of BSA or ferritin molecules conjugated to PLGA-NP was calculated by dividing the number of BSA or Ferritin molecules found in the solution (calculated from their final concentration) for the calculated average number (n) of PLGA-NPs. The average number (n) of PLGA-NPs was calculated using the following equation:

$$
n=6 m /\left(\pi \cdot D^{3} \cdot \rho\right)
$$

Equation 1

where $\mathrm{m}$ is the NP weight, $\mathrm{D}$ is the number based on mean NP diameter determined by dynamic light scattering (DLS) and $\rho$ is the NP weight per volume unit (density), estimated to be 1.1 $\mathrm{g} / \mathrm{cm}^{3}$ based on the polymer density ${ }^{46}$. The NP weight $(\mathrm{m})$ was indirectly determined by the GdDOTAMA concentration considering than about $8 \mathrm{mg}$ of GdDOTAMA are loaded into 100 mg of PLGA nanoparticles as estimated by three independent PLGA-NPs preparations, purified by dialysis without centrifugation that causes nanoparticles aggregation and loss.

\section{Cell lines}

MDA-MB-231 cells were cultured in DMEM medium containing 10\% (v/v) fetal bovine serum (FBS), $100 \mathrm{U} / \mathrm{ml}$ penicillin, $100 \mathrm{U} / \mathrm{ml}$ streptomycin, $0.01 \%$ and $4 \mathrm{mM}$ L-glutamine. MCF-7 cells were cultured in EMEM medium containing 10\% (v/v) FBS, $100 \mathrm{U} / \mathrm{ml}$ penicillin and streptomycin, $1 \%(\mathrm{v} / \mathrm{v})$ non-essential amino acid, $1 \mathrm{mM}$ sodium pyruvate, $2 \mathrm{mM}$ L-glutamine, and $0.01 \mathrm{mg} / \mathrm{ml}$ insulin. The MCF 10A cells were cultured in Dulbecco's modified Eagle's medium and Ham's F12 medium supplemented with $20 \mathrm{ng} / \mathrm{ml}$ epidermal growth factor, 100 $\mathrm{ng} / \mathrm{ml}$ cholera toxin, $0.01 \mathrm{mg} / \mathrm{ml}$ insulin, $500 \mathrm{ng} / \mathrm{ml}$ hydrocortisone and $5 \%$ of horse serum. Cells were incubated at $37^{\circ} \mathrm{C}$ under a humidified atmosphere of $5 \% \mathrm{CO}_{2}$. These cell lines were tested for mycoplasma (MycoAlertTM PLUS Mycoplasma Detection Kit, Lonza).

\section{Uptake experiments}


For PLGA-BSA and PLGA-Ferr uptake experiments, MCF-7 and MDA-MB-231 were seeded at a density of $5 \times 10^{5}$ cells in dishes of $6 \mathrm{~cm} \varnothing$ and placed in a wet $\left(37^{\circ} \mathrm{C}\right) 5 \% \mathrm{CO}_{2}$ air atmosphere incubator. For the different experiments, at $48 \mathrm{~h}$ post seeding, cells were incubated with $50 \mu \mathrm{M}$ of Gd. After $6 \mathrm{~h}$ of incubation, cells were washed three times with $10 \mathrm{ml}$ ice-cold PBS, detached with trypsin/EDTA. The Gd content in each cell line was determined by ICP-MS. For MRI analysis (see below) cells were transferred into glass capillaries. Protein concentration (proportional to the cell number) was determined from cell lysates by the Bradford assay.

\section{MRI}

All the MR images were acquired on a Bruker Avance 300 spectrometer (7T) equipped with a Micro 2.5 microimaging probe (Bruker BioSpin, Ettlingen, Germany).Glass capillaries containing about $2 \times 10^{6}$ cells were placed in an agar phantom and MR imaging was performed by using a standard $\mathrm{T}_{1}$-weighted multislice spin-echo sequence (TR/TE/ NEX $=250 / 3.7 / 8, \mathrm{FOV}$ $=1.2 \mathrm{~cm}, \mathrm{MTX}=128 \times 128, \mathrm{NEX}=$ number of excitations; FOV = field of view). The $\mathrm{T}_{1}$ relaxation times were calculated using a standard saturation recovery spin echo.

\section{Preparation and characterization of PTX loaded PLGA-NPs}

Targeted PLGA-NPs loaded with Paclitaxel were obtained using an oil-in-water $(\mathrm{o} / \mathrm{w})$ emulsion solvent extraction method. Briefly, $25 \mathrm{mg}$ of PLGA-NHS, $2.5 \mathrm{mg}$ of PTX and $3.5 \mathrm{mg}$ of GdDOTAMA were dissolved in chloroform and the same synthesis procedure described above was followed. Conjugation of ferritin or BSA to PTX loaded PLGA-NPs (PLGA-PTX-NP) was done following the procedure described above. The drug loading efficiency was determined in duplicate by HPLC on Waters Alliance-HPLC system equipped with 2695-separation module connected to 2998-photo diode array. A reverse phase Waters XBridge C18, $150 \mathrm{~mm} \times 4.6 \mathrm{~mm}$ ID, $5 \mu \mathrm{m}$ at $25^{\circ} \mathrm{C}$ was used as column. The water-acetonitrile was used as the mobile phase in gradient elution mode (acetonitrile: 0-2 $\mathrm{min}, 40 \%$, 2-10 $\mathrm{min}, 40-100 \%$ ). The effluent was monitored at $227 \mathrm{~nm}$ and flow rate was $1 \mathrm{~mL} / \mathrm{min}$. The retention time (Tr) of PTX was found to be $6.12 \mathrm{~min}$. The PTX stock solution $(1 \mathrm{mg} / \mathrm{ml})$, dissolved in acetonitrile was diluted to the range $10 \mu \mathrm{g} / \mathrm{ml}$ to $150 \mu \mathrm{g} / \mathrm{ml}$ for standard calibration curve $\left(\mathrm{R}^{2}=0.99984\right)$. $30 \mu 1$ of PLGA-PTX-NPs samples before injection were freeze-dried and then were sonicated in an ultrasonic bath in $200 \mu 1$ chloroform for $30 \mathrm{~min}$. After centrifugation at $5000 \mathrm{rpm}$ for $10 \mathrm{~min}$ and evaporation of the 
chloroform, they were sonicated again with $200 \mu$ l acetonitrile for $15 \mathrm{~min}$ and then analyzed by

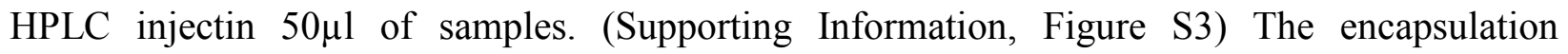
efficiency was defined by the ratio of the measured and initial amount of PTX encapsulated in the nanoparticles.

\section{In vitro drug release}

PTX-loaded nanoparticles, dissolved in HBS at a PTX concentration of $57 \mu \mathrm{g} / \mathrm{ml}$ were transferred to dialysis bags (MWCO $10000 \mathrm{Da}$ ) and placed in 1L of HBS with stirring at 110 $\mathrm{rpm}$ and $37^{\circ} \mathrm{C}$. At determined time intervals (6, 24 and $\left.48 \mathrm{~h}\right), 30 \mu \mathrm{L}$ of PLGA-PTX-Ferr and PLGA-PTX-BSA were taken and freeze-dried. Then the obtained powder was dissolved in 200 $\mu \mathrm{L}$ of chloroform by sonicating in an ultrasonic bath for $30 \mathrm{~min}$. After centrifugation at 5000 rpm for $10 \mathrm{~min}$ and chloroform evaporation, the obtained powders were dissolved in $200 \mu \mathrm{L}$ of acetonitrile, sonicated in an ultrasonic bath for $15 \mathrm{~min}$ and then analyzed by HPLC, as described above.

\section{In vitro cellular viability.}

MTT test (Sigma Aldrich) was used to evaluate the in vitro cytotoxicity of PLGA-PTX-Ferr and PLGA -PTX-BSA on MCF-7. MCF-7 cells were seeded at density of 1 x $10^{4}$ viable cells /well in 96-well plates $48 \mathrm{~h}$ before experiments. Cells were incubated for $6 \mathrm{~h}$ at increasing concentrations of nanoparticles ranging from 0 to $20 \mu \mathrm{M}$ PTX concentration. After a washing step with $100 \mu \mathrm{L}$ phosphate buffer, $10 \mu \mathrm{L}$ of MTT $(5 \mathrm{mg} / \mathrm{ml}$ in phosphate buffered saline (PBS): $\mathrm{NaCl} 0.136 \mathrm{M}$, $\mathrm{KCl} 2.7 \mathrm{mM}, \mathrm{K}_{2} \mathrm{HPO} 48.6 \mathrm{mM}, \mathrm{KH}_{2} \mathrm{PO}_{4} 1.5 \mathrm{mM}$ ) was added at $100 \mu \mathrm{L}$ of medium. After $4 \mathrm{~h}$ of incubation, the culture medium containing MTT solution was eliminated and crystals of formazan were dissolved in $150 \mu \mathrm{L}$ of dimethyl sulfoxide (DMSO). Then micro plate reader (iMark ${ }^{\mathrm{TM}}$, BioRad) was used to read it at $570 \mathrm{~nm}$ wavelength. The effect of treatment was calculated as a percentage of viability against the controls.

\section{Statistical Analysis.}

Data were expressed as means \pm SEM (standard error of the mean) or \pm SD (standard deviation of the mean), as indicated in the different determinations, calculated from at least 3 independent 
experiments. Statistical analyses were performed using the Student two-tailed t test. A p value less than 0.05 was considered statistically significant.

\title{
ACKNOWLEDGMENTS
}

This research was funded by MIUR (PRIN 2012 code 2012SK7ASN) and by the AIRC investigator Grant IG2013 n. 14565 and was also supported by Visiting Professors/Teaching Mobility programme for the academic year 2014 -2015 (financed by UNITO and Fondazione CRT). This research was performed in the framework of the Consorzio Interuniversitario di Ricerca in Chimica dei Metalli dei Sistemi Biologici (CIRCMSB).

\author{
Supporting Information. Size exclusion chromatography of PLGA nanoparticles; ${ }^{13} \mathrm{C}-\mathrm{NMR}$ \\ spectra of PLGA and PLGA-NHS (carbonylic region); HPLC chromatograms of paclitaxel \\ loaded into nanoparticles; MTT assay of MCF-7 incubated with PLGA nanoparticles not loaded \\ with paclitaxel. This material is available free of charge via the Internet at http://pubs.acs.org \\ Notes \\ The authors declare no competing financial interest.
}

\begin{abstract}
ABBREVIATIONS
PLGA, Poly (D, L-lactide-co-glicolide); PEG, poly(ethylene glycol); SCARA5, scavenger receptor class A member 5; TIM-2, T cell immunoglobulin and mucin domain-containing protein-2; TfR-1, transferrin receptors; Gd-DOTAMA, Gadolinium DOTAMA; PVA, poly(vinyl alcohol); NPs, nanoparticles; BSA, bovine serum albumin; Ferr, Ferritin; CTRL, control; MRI, magnetic resonance imaging; ICP-MS, Inductively Coupled Plasma Mass Spectrometry; HPLC, High Pressure Light Chromatography; MTT, Thiazoly Blue Tetrazolium Bromide.
\end{abstract}




\section{REFERENCES}

(1) Hare, J. I.; Lammers, T.; Ashford, M. B.; Puri, S.; Storm, G.; Barry, S. T. (2016) Challenges and strategies in anti-cancer nanomedicine development: An industry perspective. Adv. Drug. Delivery Rev. 16, 30135-1.

(2) Lammers, T.; Rizzo, L. Y.; Storm, G.; Kiessling, F. (2012) Personalized nanomedicine. Clin. Cancer Res. 18, 4889-4894.

(3) Pandita, D.; Kumar, S.; Lather, V (2015) Hybrid poly (lactic-co-glycolic acid) nanoparticles: design and delivery prospectives. Drug Discovery Today 20, 95-104.

(4) Danhier, F.; Ansorena, E.; Silva, J. M.; Coco, R.; Le Breton, A.; Préat, V. (2012) PLGAbased nanoparticles: an overview of biomedical applications. J. Controlled Release 161, 505-522

(5) Davis, M. E.; Chen, Z. G.; Shin, D. M. (2008) Nanoparticle therapeutics: An emerging treatment modality for cancer. Nat. Rev. Drug Discovery 7, 771-782.

(6) Knop, K.; Hoogenboom, R.; Fischer, D.; Schubert, U. S. (2010) Poly(ethylene glycol) in drug delivery: Pros and cons as well as potential alternatives. Angew. Chem., Int. Ed. Engl. 49, 6288-6308.

(7) Esfandyari-Manesh, M.; Mostafavi, S. H.; Majidi, R. F.; Koopaei, M. N.; Ravari, N. S.; Amini, M.; Darvishi, B.; Ostad, S. N.; Atyabi, F.; Dinarvand, R. (2015) Improved anticancer delivery of paclitaxel by albumin surface modification of PLGA Nanoparticles. Daru, J. Pharm. Sci. 23:28, 1-8.

(8) Darvishi, B.; Manoochehri, S.; Esfandyari-Manesh, M.; Samadi, N.; Amini, M.; Atyabi, F.; Dinarvand, R. (2015) Enhanced Cellular Cytotoxicity and Antibacterial Activity of 18- $\beta$ Glycyrrhetinic Acid by Albumin conjugated PLGA Nanoparticles. Drug Res. (Stuttgart, Ger.) $65,617-623$.

(9) Manoochehri, S.; Darvishi, B.; Kamalinia, G.; Amini, M.; Fallah, M.; Ostad, S. N.; Atyabi, F.; Dinarvand, R. (2013) Surface modification of PLGA nanoparticles via human serum albumin conjugation for controlled delivery of docetaxel. Daru, J. Pharm. Sci. 21:58, 1-10. 
(10) Finazzi, D.; Arosio, P. (2014) Biology of ferritin in mammals: an update on iron storage, oxidative damage and neurodegeneration. Arch. Toxicol. 88, 1787-1802.

(11) Fisher, J.; Devraj, K.; Ingram, J.; Slagle-Webb, B.; Madhankumar, A. B.; Liu, X.; Klinger, M.; Simpson, I. A.; Connor, J. R. (2007) Ferritin: a novel mechanism for delivery of iron to the brain and other organsAm. J. Physiol. Cell Physiol. 293, 641-649.

(12) Mendes-Jorge, L.; Ramos, D.; Valença, A.; López-Luppo, M.; Pires, V. M.; Catita, J.; Nacher, V.; Navarro, M.; Carretero, A.; Rodriguez-Baeza, A.; et al. (2014) L-ferritin binding to scara5: a new iron traffic pathway potentially implicated in retinopathy. PLoS ONE DOI:10.1371/journal.pone.0106974

(13) Li, J. Y.; Paragas, N.; Ned, R. M.; Qiu, A.; Viltard, M.; Leete, T.; Drexler, I. R.; Chen, X.; Sanna-Cherchi, S.; Mohammed, F.; et al. (2009) Scara5 is a ferritin receptor mediating nontransferrin iron delivery. Dev. Cell 16, 35-46.

(14) Geninatti Crich, S.; Cutrin, J. C.; Lanzardo, S.; Conti, L.; Kálmán, F. K.; Szabó, I.; Lago, N. R.; Iolascon, A.; Aime, S. (2012) Mn-loaded apoferritin: a highly sensitive MRI imaging probe for the detection and characterization of hepatocarcinoma lesions in a transgenic mouse model. Contrast Media Mol. Imaging 7, 281-288.

(15) Han, J.; Seaman, W. E.; Di, X.; Wang, W.; Willingham, M.; Torti, F. M.; Torti, S. V. (2011) Iron uptake mediated by binding of H-ferritin to the TIM-2 receptor in mouse cells. PLoS ONE DOI: 10.1371/journal.pone.0023800

(16) Li, L.; Fang, C. J.; Ryan, J. C.; Niemi, E. C.; Lebrón, J. A.; Björkman, P. J.; Arase, H.; Torti, F. M.; Torti, S. V.; Nakamura, M. C.; et al. (2010) Binding and uptake of H-ferritin are mediated by human transferrin receptor-1. Proc. Natl. Acad. Sci. U. S. A. 107, 3505-3510.

(17) Sakamoto, S.; Kawabata, H.; Masuda, T.; Uchiyama, T.; Mizumoto, C.; Ohmori, K.; Koeffler, H. P.; Kadowaki, N.; Takaori-Kondo, A. (2015) H-Ferritin Is Preferentially Incorporated by Human Erythroid Cells through Transferrin Receptor 1 in a ThresholdDependent Manner. PLoS ONE DOI: 10.1371/journal.pone.0139915

(18) Richardson, D. R.; Ponka, P. (1997) The molecular mechanisms of the metabolism and transport of iron in nor-mal and neoplastic cells. Biochim. Biophys. Acta 1331, 1-40.

(19) Lui, G. Y.; Kovacevic, Z.; Richardson, V.; Merlot, A. M.; Kalinowski, D. S.; Richardson, D. R. (2015) Targeting cancer by binding iron: Dissecting cellular signaling pathways. Oncotarget 6, 18748-18779. 
(20) Wang, W.; Knovich, M. A.; Coffman, L. G.; Torti, F. M.; Torti, S. V. (2010) Serum ferritin: Past, present and future. Biochim. Biophys. Acta 1800, 760-769.

(21) Alkhateeb, A. A.; Connor, J. R. Biochim. Biophys. Acta (2013) The significance of ferritin in cancer: anti-oxidation, inflammation and tumorigenesis.1836, 245-254.

(22) Chekhun, S. V.; Lukyanova, N. Y.; Shvets, Y. V.; Burlaka, A. P.; Buchynska, L. G. (2014) Significance of ferritin expression in formation of malignamt phenotype of human breast cancer cells Exp. Oncol. 36, 179-183.

(23) Shpyleva, S. I.; Tryndyak, V. P.; Kovalchuk, O.; Starlard-Davenport, A.; Chekhun, V. F.; Beland, F. A.; Pogribny, I. P.(2011) Role of ferritin alterations in human breast cancer cells. Breast Cancer Res. Treat 126, 63-71.

(24) Jutz, G.; van Rijn, P.; Santos Miranda, B.; Böker, A. (2015) Ferritin: a versatile building block for bionanotechnology. Chem. Rev. 115, 1653-1701.

(25) Ghisaidoobe, A. B.; Chung, S. J. (2015) Functionalized protein nanocages as a platform of targeted therapy and immunodetection. Nanomedicine (London, U. K.), 10, 3579-3595.

(26) Truffi, M.; Fiandra, L.; Sorrentino, L.; Monieri, M.; Corsi, F.; Mazzucchelli, S. (2016) Ferritin nanocages: A biological platform for drug delivery, imaging and theranostics in cancer. Pharmacol. Res. 107, 57-65.

(27) Kálmán, F.K.; Geninatti Crich, S.; Aime, S.; (2010) Reduction/dissolution of a beta$\mathrm{MnOOH}$ nanophase in the ferritin cavity to yield a highly sensitive, biologically compatible magnetic resonance imaging agent. Angew Chem Int Ed Engl. 49, 612-5.

(28) Geninatti Crich, S.; Cadenazzi, M.; Lanzardo, S.; Conti, L.; Ruiu, R.; Alberti, D.; Cavallo, F.; Cutrin, J. C.; Aime, S. (2015) Targeting ferritin receptors for the selective delivery of imaging and therapeutic agents to breast cancer cells. Nanoscale 7, 6527-6533.

(29) Fonseca, C.; Simões, S.; Gaspar, R. J. (2002) Paclitaxel-loaded PLGA nanoparticles: preparation, physicochemical characterization and in vitro anti-tumoral activity Controlled Release 83, 273-286.

(30) Mariano, R. N.; Alberti, D.; Cutrin, J. C.; Geninatti Crich, S.; Aime, S. (2014) Design of PLGA based nanoparticles for imaging guided applications. Mol. Pharmaceutics 11, 4100-4106.

(31) Sahoo, S. K.; Panyam, J.; Prabha, S.; Labhasetwar, V.(2002) Residual polyvinyl alcohol associated with poly (D,L-lactide-co-glycolide) nanoparticles affects their physical properties and cellular uptake J.Controlled Release 82, 105-114. 
(32) Cheng, J.; Teply, B. A.; Sherifi, I.; Sung, J.; Luther, G.; Gu, F. X.; Levy-Nissenbaum, E.; Radovic-Moreno, A. F.; Langer, R.; Farokhzad, O. C. (2007) Formulation of functionalized PLGA-PEG nanoparticles for in vivo targeted drug delivery Biomaterials 28, 869-876.

(33) Tuyen Dao, T. P.; Hoai Nguyen, T.; To, V. V.; Ho, T. H.; Nguyen, T. A.; Chien Dang, M. A new formulation of curcumin using poly(lactic-co-glycolic acid)-polyethylene glycol diblock copolymer as carrier material (2014) Adv. Nat. Sci.: Nanosci. Nanotechnol. DOI:10.1088/2043-6262/5/3/035013

(34) Boddu, S. H. S.; Vaishya, R.; Jwala, J.; Vadlapudi, A.; Pal, D.; Mitra, A. K. (2012) Preparation and Characterization of Folate Conjugated Nanoparticles of Doxorubicin using PlgaPeg-Fol Polymer Med. Chem. 2, 68-75.

(35) Gossmann R, Fahrländer E, Hummel M, Mulac D, Brockmeyer J, Langer K., Eur J Pharm Biopharm. 2015 Jun;93:80-7. doi: 10.1016/j.ejpb.2015.03.021; Adsorption of plasma proteins on uncoated PLGA nanoparticles.

(36) Sempf K, Arrey T, Gelperina S, Schorge T, Meyer B, Karas M, Kreuter J. Eur J Pharm Biopharm. 2013 Sep;85(1):53-60. doi: 10.1016/j.ejpb.2012.11.030.).

(37) Esposito, G.; Geninatti Crich, S.; Aime, S.; (2008) Efficient cellular labeling by CD44 receptor-mediated uptake of cationic liposomes functionalized with hyaluronic acid and loaded with MRI contrast agents. ChemMedChem. 3, 1858-62

(38) Huang, CH.; Tsourkas, A.; (2013) Gd-based macromolecules and nanoparticles as magnetic resonance contrast agents for molecular imaging Curr Top Med Chem, 13, 411-421.

(39) Rowinsky, E. K.; Donehower, R. C. (1995) Paclitaxel (taxol). N. Engl. J. Med. 332, 1004-1014.

(40) Gelderblom, H.; Verweij, J.; van Zomeren, D. M.; Buijs, D.; Ouwens, L.; Nooter, K.; Stoter, G.; Sparreboom, A. (2002) Influence of Cremophor El on the bioavailability of intraperitoneal paclitaxel. Clin. Cancer Res. 8, 1237-1241.

(41) Weiss, R. B.; Donehower, R. C.; Wiernik, P. H.; Ohnuma, T.; Gralla, R. J.; Trump, D. L.; Baker, J. R. Jr.; Van Echo, D.A.; Von Hoff, D. D.; Leyland-Jones, B. (1990) Hypersensitivity reactions from taxol J. Clin. Oncol. 8, 1263-1268.

(42) Averineni, R. K.; Shavi, G. V.; Gurram, A. K.; Deshpande, P. V.; Arumugam, K.; Maliyakkal, N.; Meka, S. R.; Nayanabhirama, U. (2012) PLGA 50:50 nanoparticles of 
paclitaxel: Development, in vitro anti-tumor activity in BT-549 cells and in vivo evaluation Bull. Mater. Sci. 35, 319-326.

(41) Chittasupho, C.; Lirdprapamongkol, K.; Kewsuwan, P.; Sarisuta, N. (2014) Targeted delivery of doxorubicin to A549 lung cancer cells by CXCR4 antagonist conjugated PLGA nanoparticles. Eur. J. Pharm. Biopharm. 88, 529-538.

(42) Shah, N.; Chaudhari, K.; Dantuluri, P.; Murthy, R. S.; Das, S. (2009) Paclitaxel-loaded PLGA nanoparticles surface modified with transferrin and Pluronic((R))P85, an in vitro cell line and in vivo biodistribution studies on rat model. J. Drug Targeting 17, 533-542.

(43) Yu, K.; Zhao, J.; Zhang, Z.; Gao, Y.; Zhou, Y.; Teng, L.; Li, Y. (2016)Enhanced delivery of Paclitaxel using electrostatically-conjugated Herceptin-bearing PEI/PLGA nanoparticles against HER-positive breast cancer cells. Int. J. Pharm. 497, 78-87.

(44) Danhier, F.,Lecouturier, N., Vroman, B., Jèrôme, C., Marchand-Brynaert, J., Feron, O., Préat, V. (2009) Paclitaxel-loaded PEGylated PLGA-based nanoparticles: in vitro and in vivo evaluation. J. Controlled Release, 133, 11-17.

(45) Anelli, PL.; Lattuada, L; Lorusso, V; Schneider, M; Tournier, H; Uggeri, F; (2001) Mixed micelles containing lipophilic gadolinium complexes as MRA contrast agents. Magma 12, 114-20.

(46) Sahoo, S. K.; Ma, W.; Labhasetwar, V. (2004) Efficacy of transferrin-conjugated paclitaxel-loaded nanoparticles in a murine model of prostate cancer Int. J. Cancer 112, 335-340. 


\section{Table of Contents Graphic}

Innovative PLGA based theranostic nanoparticles with improved anticancer drug delivery by Ferritin surface modification

Ludmila N. Turino, Maria R. Ruggiero, Rachele Stefanìa, Juan C. Cutrin, Silvio Aime, Simonetta Geninatti Crich

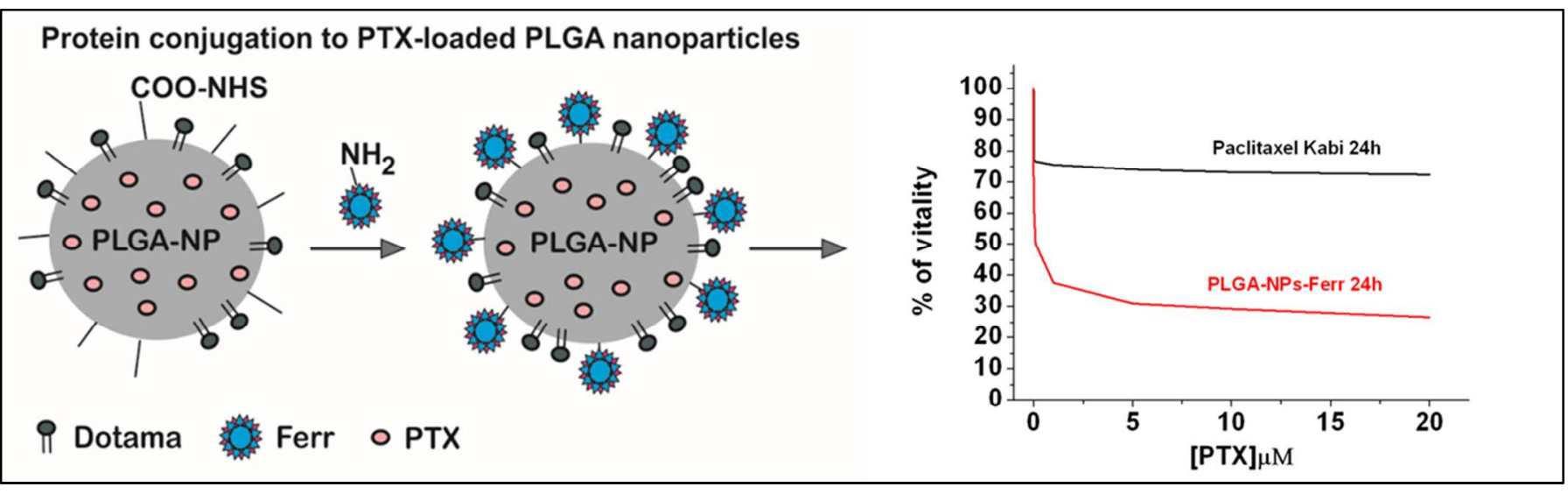


A)

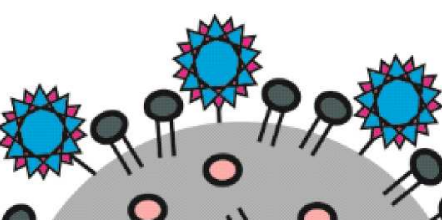

Q 0 \% 0 Gd-DOTAMA

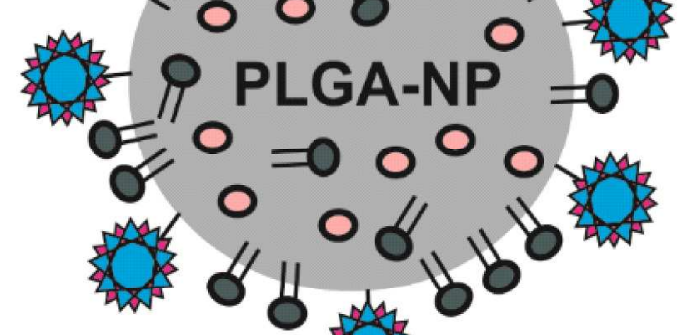

B)

Figure 1. A) Schematic representation of PLGA-NPs-Ferr nanoparticles; B) Schematic representation of GdDOTAMA.

$303 \times 291 \mathrm{~mm}(300 \times 300 \mathrm{DPI})$ 

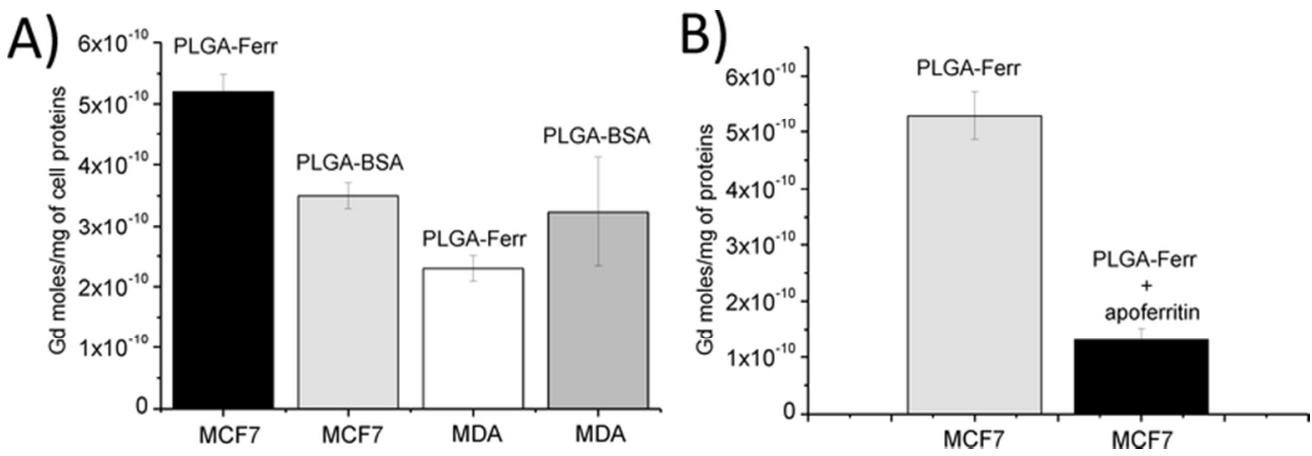

Figure2. (A) ICP-MS determination of the intracellular Gd content of MCF7 and MDA-MB-231 cells cultured for $6 \mathrm{~h}$ with PLGA-Ferr and PLGA-BSA $50 \mu \mathrm{M}$ in $\mathrm{Gd}$. (B) Competition experiment on MCF7 cells. ICP-MS measurements of intracellular Gd were done with or without the addition of an excess (75 times) of native ferritin. Graphs show the mean \pm SEM of internalized Gd moles every $\mathrm{mg}$ of total cell proteins from 3 independent experiments.

$69 \times 23 \mathrm{~mm}(300 \times 300 \mathrm{DPI})$ 


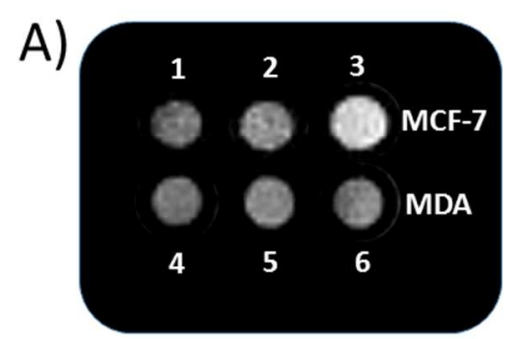

B)

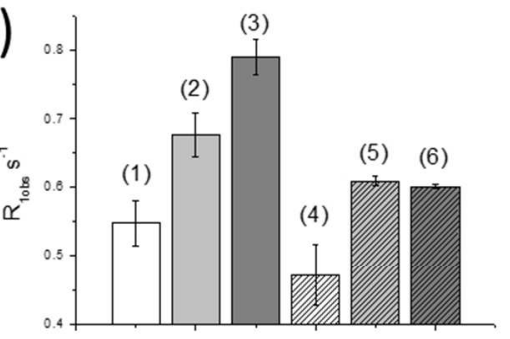

Figure 3. A) Representative T1-weighted spin echo image (acquired at $7 \mathrm{~T}$ ) of glass capillaries containing MCF7 $(1,2,3)$ and MDA-MB-231 $(4,5,6)$ cells incubated for 6 hours in the absence $(1,4$ controls) and in the presence of PLGA-BSA $(2,5)$ and PLGA-Ferr $(3,6)$. B) R1obs (s-1) measured on cell pellets using a saturation recovery sequence. The histogram shows the mean \pm SD of R1obs from 3 independent experiments. 
Figure 4: In vitro drug release from PLGA-PTX-CTRL, PLGA-PTX-Ferr and PLGA-PTX-BSA evaluated at different time $(6,24,48 \mathrm{~h})$ under dialysis in PBS at $37^{\circ} \mathrm{C}, \mathrm{pH}=7.4$. Graphs show the mean \pm SD of $\%$ PTX release obtained by 3 independent experiments.

$$
288 \times 201 \mathrm{~mm}(300 \times 300 \mathrm{DPI})
$$


1

2

3

4

5

6

7

8

9

10

11

12

13

14

15

16

17

18

19

20

21

22

23

24

25

26

27

28

29

30

31

32

33

34

35

36

37

38

39

40

41

42

43

44

45

46

47

48

49

50

51

52

53

54

55

56

57

58

59

60
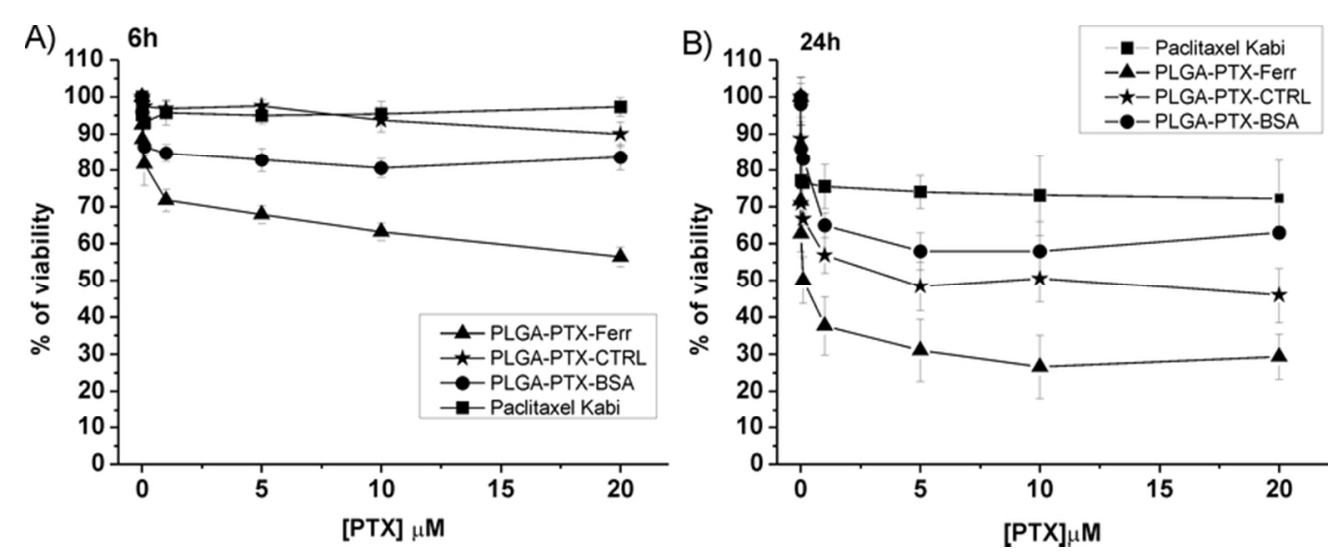

Figure5. Percentage of viability (measured with MTT assay) of MCF-7 after $6 \mathrm{~h}$ (A) and $24 \mathrm{~h}$ (B) of incubation at different concentration of PLGA-PTX-CTRL, PLGA-PTX-Ferr, PLGA-PTX-BSA and Paclitaxel Kabi. Graphs show the mean \pm SEM of \% viability evaluated on 3 independent experiments.

$74 \times 29 \mathrm{~mm}$ (300 x 300 DPI) 
Figure 6. Percentage of viability of MCF-7 and MCF-10A after $6 \mathrm{~h}$ and $24 \mathrm{~h}$ of incubation at different concentration of PLGA-PTX-Ferr. Graphs show the mean \pm SEM of \% viability evaluated on 3 independent experiments.

$288 \times 201 \mathrm{~mm}(300 \times 300 \mathrm{DPI})$ 